\title{
Clínica de tamiz auditivo
}

\author{
Dr. Luis Oscar González-González* Lic. Martha Victoria Pérez-González, ${ }^{* *}$ Lic. Adriana Aguilar-Chávez ${ }^{* * *}$
}

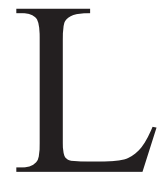

a creación de la Clínica de Tamiz Auditivo (CLITA), surge por la necesidad de detectar, prevenir y corregir las alteraciones auditivas de los pacientes hospitalizados en el Instituto Nacional de Pediatría (INP). Estos pequeños tienen múltiples factores de riesgo para sufrir un daño auditivo. Lo que importa es tratar de evitar las repercusiones de la baja de audición o la pérdida de esta función, con una intervención interdisciplinaria oportuna.

El lenguaje hablado es la mayor forma de comunicación del humano. Esta facultad que se adquiere en los primeros años de vida y se va especializando, refinando y ampliando con la edad. Cualquier alteración en la audición causa un retraso del lenguaje.

La alteración auditiva no es un trastorno aislado, de retraso auditivo verbal; también afecta el entorno familiar, social y educativo. Algunas destrezas motoras evolucionan al mismo tiempo que el desarrollo del lenguaje y pueden verse afectadas por un retraso del habla.

Los pacientes hospitalizados en el INP, tienen mayor riesgo de sufrir este retraso por una lesión auditiva derivada de las enfermedades que padecen que pueden ser infecciosas, neurológicas, traumáticas, metabólicas, por prematurez etc. o causada por el empleo de fármacos con aminoglucósidos, diuréticos, quimioterápicos, etc.

Como proyecto para la detección de hipoacusia en recién nacidos en hospitales maternoinfantiles de segundo y tercer nivel del Gobierno Federal, ya existe un programa de tamiz auditivo neonatal, pero no existe uno para detectar lesiones auditivas en niños con diversas patologías, hospitalizados en instituciones de tercer nivel de atención,

* Coordinador de la Clínica de Tamiz Auditivo

www.nietoeditores.com.mx no sólo limitado a pacientes tratados con quimioterapia, sino para pacientes en terapia intensiva neonatal o pacientes con algún riesgo auditivo. Con estructura y personal capacitado para este fin, en el INP, el Servicio de Otorrinolaringología y Neurofisiología se unen para la creación de una nueva clínica.

La CLITA es el resultado de la conjunción de dos servicios del INP: El de Neurofisiología, cuya titular es la Dra. María Aurora García Briceño y el de Otorrinolaringología cuyo Jefe es el Dr. Juan Gutiérrez Butanda. Para llevar a cabo el tamiz auditivo de los pacientes, la nueva Clínica de Tamiz Auditivo cuenta con el siguiente personal: Un médico especialista, encargado responsable de la Clínica *, una técnica licenciada en Lingüística, quien realizará los estudios **, una licenciada Terapeuta en Comunicación Humana ***, encargada de la terapia del lenguaje. Se cuenta con la tecnología más avanzada para el diagnóstico de las alteraciones auditivas. En el Servicio de Otorrinolaringología hay equipo portátil de emisiones otoacústicas, de productos de distorsión, y transientes; equipo de timpanometría, reflejos estapediales, potenciales, estado estable, audiometría tonal y logoaudiometría. Además, en el Servicio de Neurofisiología se emplearán potenciales auditivos provocados de latencia corta.

Las acciones de la CLITA son: 1. Detección temprana de lesiones auditivas uni o bilaterales, confirmación del diagnóstico de la pérdida auditiva y sus diferentes grados, vigilancia audiológica y de terapia del lenguaje; estimulación temprana o física según sea el caso. 2. Prevención: Cuando es posible, administrar otoprotectores. 3. Corrección: Adaptando un auxiliar auditivo eléctrico al o los oídos afectados conjuntamente con la terapia del lenguaje.

La figura 1 ilustra el flujograma de acción de la CLITA. 


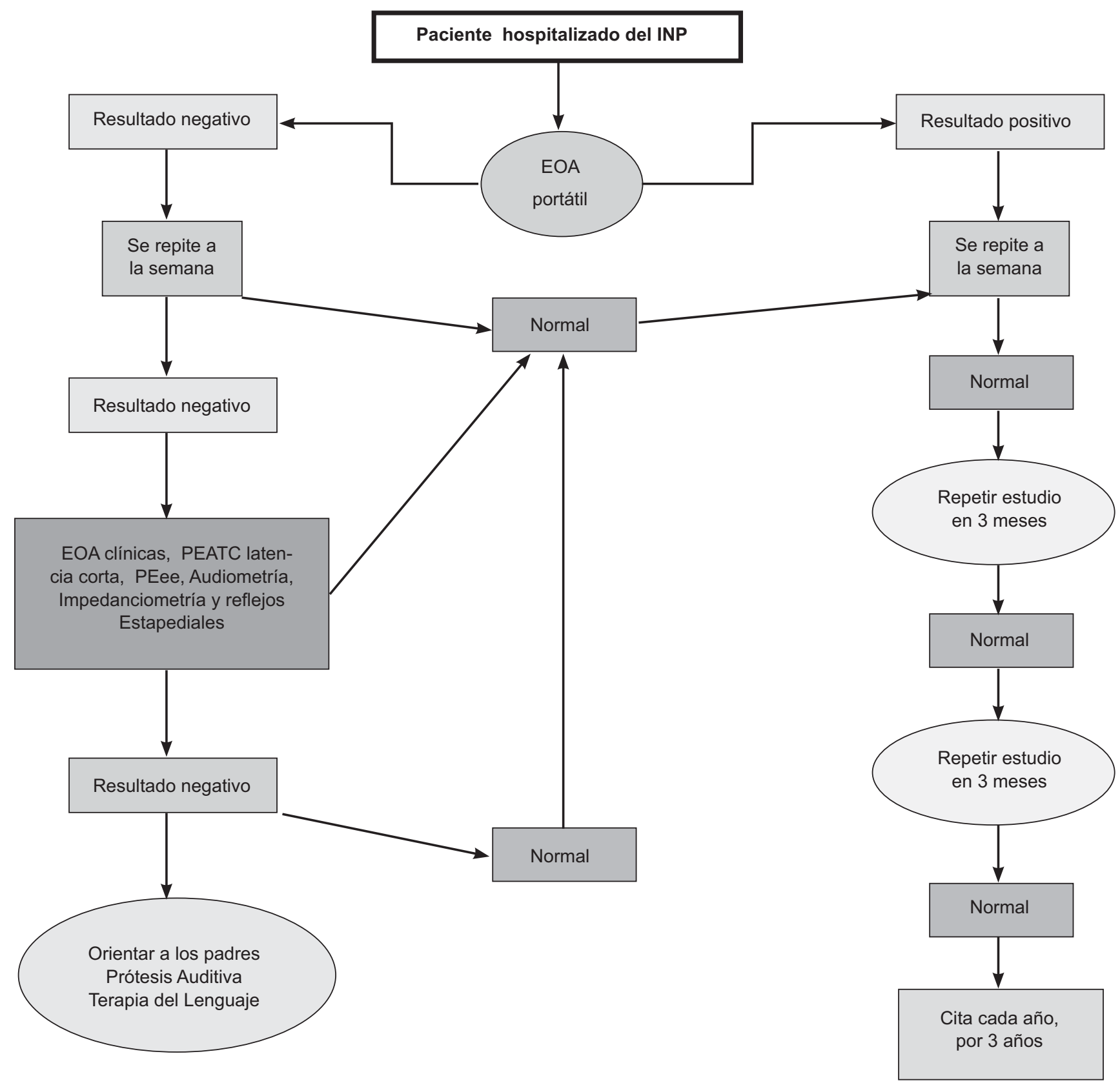

Figura 1.

\section{REFERENCIAS}

1. Godoy J, Sierra M, Martínez J. Programa de screening auditivo en recién nacidos de Clínica Las Condes-Chile. Rev Med Clin Las Condes. 2003;14:1.

2. American Academy of Pediatrics, Joint Committee on Infant Hearing. Position Statement 1994. Pediatrics. 1995;95:1526.

3. Comisión para la detección precoz de la hipoacusia (CODE$\mathrm{PEH}$ ). Propuesta para la detección precoz de la hipoacusia infantil. An Esp Pediatr. 1999:51(4):336-44.
4. Joint Committee on Infant Hearing; American Academy of Audiology; American Academy of Pediatrics; American Speech-Languaje-Hearing Association: directors of Speech and Hearing Programs in State Health and Welfare Agencies. Year 2000 position statement: principles and guidelines for early hearing detection and intervention programs. Pediatrics. 2000; 106(4):798-817.

5. Ferdinando G, Mark E. European Consensus statement on Neonatal Hearing Screening finalized at the European Consensus development Conference on Neonatal Hearing Screening. Milan. 1998. 